\title{
On Finding a Better Way
}

The cost of health care in the Unites States continues to exceed that of all other wealthy, industrialized nations reporting data to the Organization of Economic Cooperation and Development (OECD). It is estimated that the United States spent $>17 \%$ of its gross domestic product on health care in 2019, roughly twice the OECD average. ${ }^{1}$ Hospital costs represent $33 \%$ of total spending in the United States, with in-patient hospitalization prices rising 32\% from 2012 to $2018 .^{2}$ Despite this higher spending, the United States ranks last in access to health care, equitable treatment, and outcomes. $^{3}$

By far the predominant role for respiratory therapists in the United States is caring for hospital in-patients. ${ }^{4}$ This fact has been evident during the COVID-19 pandemic, where respiratory therapists have worked long and hard to care for their patients under very stressful conditions. Since Edwin R. Levine MD began teaching inhalation therapy at Michael Reese Hospital in Chicago over 75 years ago, respiratory therapists have embraced innovation and new information in technology, patient care, and community health to add value to the services they provide. Desautels and colleagues ${ }^{5}$ describing the use of intermittent mandatory ventilation in 1973, Nielsen-Tietsort et $\mathrm{al}^{6}$ introducing respiratory care protocols in 1981, Hess and Kauffman ${ }^{7}$ describing a method to monitor infant airway pressure during manual ventilation in 1982, Kacmarek and colleagues ${ }^{8}$ illustrating doseresponse of inhaled nitric oxide in 1993, and the premonitory body of work by Branson and colleagues ${ }^{9-11}$ on mechanical ventilation in mass casualty respiratory failure in the 2000s are all shining examples. Innovation and value in clinical practice, however, are often not as readily apparent as a technological breakthrough or a dramatically elevated scope of practice. The literature suggests that most innovative ideas introduced into practice rise from collaborative processes cultivated within an environment that supports the sharing of knowledge. ${ }^{12}$ Stoller and colleagues ${ }^{13}$ at the Cleveland Clinic demonstrated this by identifying features of respiratory care teams with

Dr Berlin has disclosed relationships with Vero Biotech, PN Medical, Athletic Heart Cardiac \& Metabolic Testing, and Convergent Engineering.

Correspondence: Thomas Berlin DHSc MSc RRT. E-mail: tom.berlin@ adventhealth.com.

DOI: $10.4187 /$ respcare. 08891 a successful culture for change. These included a clear vision; a propensity for knowledge, data, and evidence acquisition; cultivation of ownership and empowerment; collaboration; and relentless communication, among others.

\section{See the Original Study on Page 357}

In this issue of RESPIRATORY CARE, Jackson et $\mathrm{al}^{14}$ present a descriptive study to detail the education and implementation processes to safely and effectively provide high-flow nasal cannula (HFNC) therapy to subjects outside of the ICU. The authors' stated objectives were to improve patient outcomes, reduce ICU-associated costs, and ease ICU bed availability in a tertiary medical center where HFNC therapy was previously administered only in the ICU. This project arose from an issue common in hospitals in the United States and throughout the world: a supply of intensive care resources insufficient to meet the needs of patients requiring such levels of care, an issue that is particularly apparent during the COVID-19 pandemic. ${ }^{15}$ With these objectives in mind, the interprofessional research team devised a robust protocol and education plan to prepare nonintensive care personnel to care for patients who would benefit from HFNC therapy but did not otherwise require an intensive level of care and monitoring. Comprehensive education was provided first to respiratory therapists, and then by respiratory therapists to nurses and physicians. Nursing staff preparedness and a heightened awareness and rounding frequency by the respiratory therapists helped achieve the desired results. The authors observed that two thirds of study subjects received all care outside of the ICU, saving 486 ICU days during the study period. ${ }^{14}$

It was recognized early that appropriate patient selection was paramount for patient safety and for the success of the endeavor. HFNC therapy is becoming a standard intervention in cases of de novo hypoxemic respiratory failure; when compared to conventional oxygen therapy, its use has resulted in a reduced need for endotracheal intubation without increasing mortality. ${ }^{16,17}$ As Jackson et $\mathrm{al}^{14}$ report, patients responding to this high inspiratory gas flow and undiluted $\mathrm{F}_{\mathrm{IO}_{2}}$ who, based upon careful assessment, do not require other life-saving interventions or intensive physiologic monitoring, may fare well outside of the ICU. With the cost of care in the ICU reported to be 3 times that of 


\section{EDITORIALS}

non-ICU care $^{18}$ the reader could assume a significant expense reduction was realized due to ICU avoidance.

Because HFNC therapy is a service typically provided by respiratory therapists, this study provides a simple yet clear example of the innovation and value a progressive and collegial respiratory therapy team can provide their institution and community. While we recognize that therapists elsewhere may have previously instituted such a practice within their hospital, the authors have provided a template for others to follow in pursuit of such increased value within their own institution. Innovation need only go as far as your practice and workplace to create added value. One may ask the question: What other services can respiratory therapists provide or redesign to reduce cost, improve outcomes, or otherwise add value for the patients, institutions, and communities they serve? Initiation of a ventilator liberation protocol using the $\mathrm{ABCDEF}$ bundle ${ }^{19}$ to reduce ICU length of stay, development of a telehealth-based outpatient pulmonary rehabilitation program to improve access for patients with chronic lung disease or COVID-19 sequelae, ${ }^{20}$ or opening a community lung clinic for the underserved population to mitigate emergency department visits and hospitalization are all ideas brought to fruition. With hospital care becoming increasingly unaffordable, now is the time for forward-thinking respiratory therapists to expand upon their heritage and clearly and convincingly demonstrate the value they bring. An opportunity awaits!

\section{Thomas Berlin Pulmonary \& Respiratory Care AdventHealth Orlando Orlando, Florida}

\section{REFERENCES}

1. Organization of Economic Cooperation and Development. Spending on health: latest trends. Available at: www.oecd.org/health/healthsystems/Health-Spending-Latest-Trends-Brief.pdf. Accessed December $15,2020$.

2. Hartman M, Martin A, Benson J, Catlin A, National Health Expenditure Accounts Team. National health care spending in 2018: growth driven by accelerations in Medicare and private insurance spending. Health Aff (Millwood) 2020;39(1):8-17.

3. Schreider EC, Sarnak DO, Squires D, Shah A, Doty MM. Mirror, mirror 2017: international comparison reflects flaws and opportunities for better U.S. health care. Available at: www.hcfat.org/Mirror_Mirror_ 2017_International_Comparison.pdf. Accessed December 15, 2020.
4. Bureau of Labor Statistics, U.S. Department of Labor. Occupational outlook handbook, respiratory therapists. Available at: https://www. bls.gov/ooh/healthcare/respiratory-therapists.htm. Accessed December $15,2020$.

5. Downs JB, Klein EF Jr, Desautels D, Modell JH, Kirby RR. Intermittent mandatory ventilation: a new approach to weaning patients from mechanical ventilators. Chest 1973;64(3):331-335.

6. Nielsen-Tietsort J, Poole B, Creagh CE, Repsher LE. Respiratory care protocol: an approach to in-hospital respiratory therapy. Respir Care 1981;26(5):430-436.

7. Kauffman G, Hess DR. Modification of the infant Laerdal resuscitation bag to monitor airway pressure. Crit Care Med 1982;10(2):112113.

8. Bigatello LM, Hurford WE, Kacmarek RM, Roberts JD Jr, Zapol WM. Prolonged inhalation of low concentrations of nitric oxide in patients with severe adult respiratory distress syndrome. Anesthesiology 1994;80(4):761-770.

9. Rubinson L, Branson RD, Pesik N, Talmor D. Positive pressure ventilation equipment for mass casualty respiratory failure. Biosecur Bioterror 2006;4(2):183-194.

10. Daugherty EL, Branson R, Rubinson L. Mass casualty respiratory failure. Curr Opin Crit Care 2007;13(1):51-56.

11. Branson RD, Johannigman JA, Daugherty EL, Rubinson L. Surge capacity mechanical ventilation. Respir Care 2008;53(1):78-88.

12. Johnson SB. Where good ideas come from: the natural history of innovation. New York: Penguin; 2011.

13. Stoller JK, Kester L, Roberts VT, Orens DK, Babic MD, Lemin ME, et al. An analysis of features of respiratory therapy departments that are avid for change. Respir Care 2008;53(7):871-884.

14. Jackson JA, Spilman SK, Kingery LK, Oetting TW, Taylor MJ, Pruett WM, et al. Implementation of high-flow nasal cannula therapy outside the intensive care unit. Respir Care 2021;66(3):357-365.

15. Valley TS, Noritomi DT. ICU beds: less is more? Yes. Intensive Care Med 2020;46(8):1594-1596.

16. Rochwerg B, Granton D, Wang DX, Helviz Y, Einav S, Frat JP, et al. High-flow nasal cannula compared with conventional oxygen therapy for acute hypoxemic respiratory failure: a systematic review and metaanalysis. Intensive Care Med 2019;45(5):563-572.

17. Agarwal A, Basmaji J, Muttalib F, Granton D, Chaudhuri D, Chetan D, et al. High-flow nasal cannula for acute hypoxemic respiratory failure in patients with COVID-19: systematic reviews of effectiveness and its risks of aerosolization, dispersion, and infection transmission. Can J Anaesth 2020;67(9):1217-1248.

18. Halpern N, Pastores SM. Critical care medicine beds, use, occupancy and costs in the United States: a methodological review. Crit Care Med 2015;43(11):2452-2459.

19. Pun BT, Balas MC, Barnes-Daly MA, Thompson JL, Aldrich JM, Barr J, et al. Caring for critically ill patients with the ABCDEF Bundle: result of the ICU Liberation Collaborative in over 15,000 adults. Crit Care Med 2019;47(1):3-14.

20. Wooten SL, King M, Alison JA, Mahadev S, Chan ASL. COVID-19 rehabilitation delivered via a telehealth pulmonary rehabilitation model: a case series. Respirol Case Rep 2020;8(8):1-6. 